\title{
Energy Harvesting Strategy Using Piezoelectric Element Driven by Vibration Method
}

\author{
Dong-Gun Kim, So-Nam Yun, Young-Bog Ham, Jung-Ho Park \\ Energy Plant Research Div., Korea Institute of Machinery\& Materials, Daejeon, Korea \\ E-mail: \{dgkim82,ysn688,hyb665\}@kimm.re.kr \\ Received October 28, 2009; revised November 17, 2009; accepted December 8, 2009
}

\begin{abstract}
This study demonstrates a method for harvesting the electrical power by the piezoelectric actuator from vibration energy. This paper presents the energy harvesting technique using the piezoelectric element of a bimorph type driven by a geared motor and a vibrator. The geared motor is a type of PWM controlled device that is a combination of an oval shape cam with five gears and a speed controller. When using the geared motor, the piezoelectric element is size of $36 \mathrm{~L} \times 13 \mathrm{~W} \times 0.6 \mathrm{H}$. The output voltage characteristics of the piezoelectric element were investigated in terms of the displacement and vibration. When using the vibrator, the electric power harvesting is based on piezoelectric effect and piezoelectric vibrator consists of a magnetic type oscillator, a cantilever, a bimorph actuator and controllers. Low frequency operating technique using piezoelectric vibrator is very important because normal vibration sources in the environment such as building, human body, windmill and ship have low frequency characteristics. We can know from this study results that there are many energy sources such as vibration, wind power and wave power. Also, these can be used to the energy harvesting system using smart device like piezoelectric element.
\end{abstract}

Keywords: Energy Harvester, Piezoelectric Element, Wind Energy, Vibration Energy, USN

\section{Introduction}

The Brilliant technological advancements have allowed low-power consuming elements and modules to be developed, and the Ubiquitous Sensor Network (USN), to be commercialized in 2010, is attracting a high level of interest. The USN is an intelligent social infrastructure that can create information and knowledge from situation perceptions, by detecting, saving, processing and integrating the objects and environmental information obtained through tags and sensor nodes, which are maintained in many locations.

However, when a battery or electrical wires are used to drive the sensor nodes in the USN, it can become quite costly, as well as damaging to the environment. Recognition of this fact has led to the pursuit of studies on wireless energy harvesters that can easily convert energy sources such as solar energy, vibration, heat, wind power or wave energy, which can be commonly found in the environment, into electricity [1-3].

An example of this type of research is the energy harvesting devices invented by a group of MIT researchers. The researchers inserted devices under the sole of shoes, one of which used PZT and the other of which used
PVDF. They reported that when using PZT, the maximum voltage of PZT was $150 \mathrm{~V}$ at a load resistance of $250 \mathrm{k} \Omega$. In this case, the maximum electricity was recorded as $80 \mathrm{~mW}$, and the average electricity was $1.8 \mathrm{~mW}$. For PVDF, the maximum voltage was $60 \mathrm{~V}$ at a load resistance of $250 \mathrm{k} \Omega$. In this case, the maximum electricity was recorded to be $20 \mathrm{~mW}$, and the average electricity to be $1.1 \mathrm{Mw}[4,5]$.

At Nebraska University (U.S.), Prof. Stephen R. Platt et al. conducted, by inserting an energy harvester into a keen joint, a study on a PZT energy harvester to be used as the energy source for a sensor and microprocessor that can convey the information of the status of the energy harvester using the electricity converted from the force put on the knee joint [6]. Shashank Priya of Texas University (U.S.) suggested a theoretical model to calculate electricity generated from a piezoelectric bimorph element in the low frequency band, and announced that it is possible to generate $7.5 \mathrm{~mW}$ of electricity at a wind velocity of $10 \mathrm{mph}$ when a prototype windmill was used to verify the theoretical analysis [7].

These devices are some examples of power generation based on the PZT method, which converts unconsciously wasted energy such as human power, vibration, wind 
power, or wave power into electricity using a simple structure. Representative materials for piezoelectric elements include $\mathrm{Pb}(\mathrm{ZrTi}) \mathrm{O}_{3}$, and PVDF. A great deal of research has been conducted to investigate methods for maximizing the effectiveness of piezoelectric power generation. This paper suggests a method of generating electrical energy with a piezoelectric ceramic using wind, an energy source that is easily applied and from which we can obtain "clean" energy [8].

A characteristic of the piezoelectric ceramic is that it is very difficult to generate energy using small vibrations. Worse still, the piezoelectric ceramic will break when it is the object of a large deformation. This paper presents the energy harvesting technique using the piezoelectric actuator of a bimorph type driven by a geared motor and a vibrator. The geared motor of this study is an equivalent model of the windmill which is rotated by natural wind. The geared motor is a type of PWM controlled device that is a combination of an oval shape cam with five gears and a speed controller. The piezoelectric element is a size of $36 \mathrm{~L} \times 13 \mathrm{~W} \times 0.6 \mathrm{H}$. The output voltage characteristics of the piezoelectric element were investigated in terms of the displacement and vibration. The experiments were performed at the geared motor rpm of $40,81,126,172 \mathrm{rpm}$ and the piezoelectric element displacement of $100 \mu \mathrm{m}, 200 \mu \mathrm{m}, 300 \mu \mathrm{m}, 400 \mu \mathrm{m}, 500 \mu \mathrm{m}$. The power of $0.068 \mathrm{~mW}$ was generated in the motor speed of $172 \mathrm{rpm}$ and the piezoelectric element displacement of $500 \mu \mathrm{m}$. The piezoelectric cantilever (the method by which a piezoelectric element can be attached to a long board with good elasticity) was applied in order to complement this weakness, improve the efficiency of energy harvesting, and effectively convey the mechanical energy to the piezoelectric element.

In addition, to efficiently deliver the mechanical energy to the piezoelectric cantilever, resonance, which is generated only when the natural frequency of the piezoelectric cantilever is the same as the vibration source, should be generated. However, the natural frequency of the piezoelectric element is higher than the 10 to $300 \mathrm{~Hz}$ generated by the electric products, such as buildings, automobiles, airplanes, refrigerators and washing machines, on which an energy harvester can be attached. As such, the natural frequency of the piezoelectric element should be lowered, so that it can be attached to such places. There are several ways that have been suggested to lower the natural frequency of a piezoelectric cantilever, including lengthening the cantilever or making the end weight heavier.

\section{Experimental Apparatus}

\subsection{Type of Geared Motor}

Figure 1 shows the block diagram of geared motor type energy harvester which consists of the energy conversion setup using a geared motor, energy accumulating part and data measuring part. Experimental setup for energy conversion consists of electric energy storage part which is generated by piezoelectric effect, measuring part of piezoelectric element output voltage and displacement measuring part of the piezoelectric element which is caused by a geared motor operation.

Figure 2 shows the photos of the experimental setup for energy conversion and the measuring equipment of output voltage and displacement of the piezoelectric element respectively. In the Figure 2 with energy conversion experimental setup, $36 \mathrm{~L} \times 13 \mathrm{~W} \times 0.6 \mathrm{H}$ of piezoelectric element and geared motor which has a reduction ratio 1:36 were used. The revolution of geared motor was controlled by PWM method. The displacement ranges were adjusted in the 0 to $600 \mu \mathrm{m}$ for brittleness of the study object piezoelectric element.

Figure 3 shows the energy storage circuit. Bridge diode and condenser were used for voltage change $\mathrm{AC}$ to

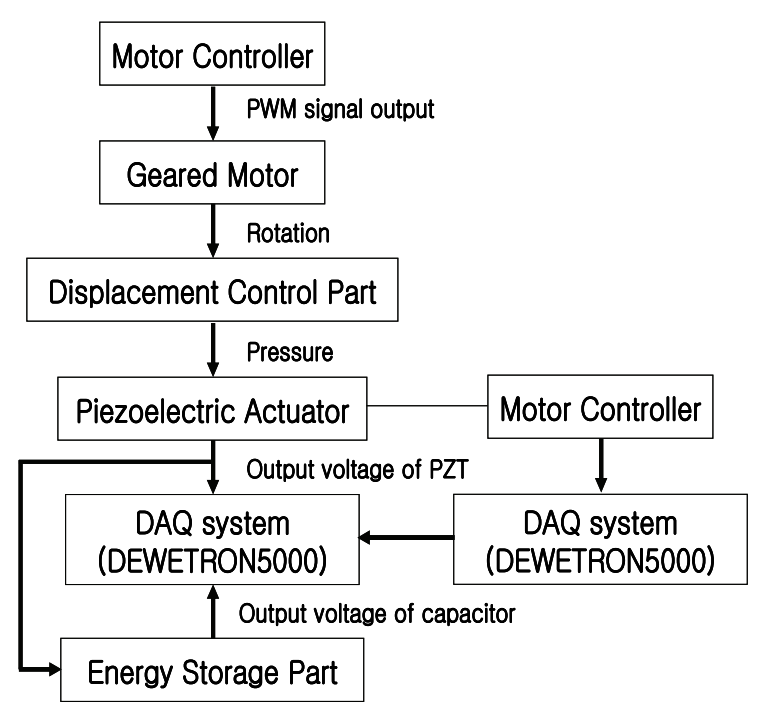

Figure 1. Block diagram of test system and measuring equipment.

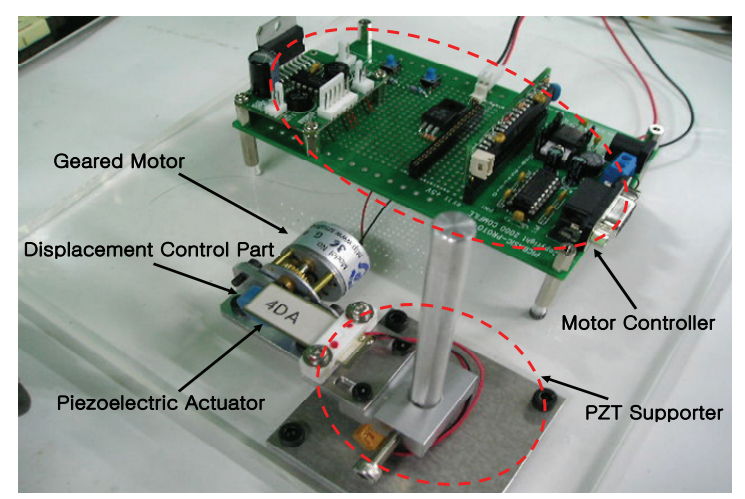

Figure 2. Energy conversion test system. 
DC. In the Figure 3, upper circuit shows the rectified one using bridge diode and lower circuit shows the condenser one for filtering the DC voltage fluctuation.

Experiments were operated by three cases.

First, one condition of the variables of piezoelectric element displacement or geared motor speed was fixed and the output voltage from piezoelectric element by change the range variation of an anther condition was measured. Displacement and output voltage of the piezoelectric element were recorded through the A/D converter. Displacement ranges of experimental piezoelectric element were from $100 \mu \mathrm{m}$ to $500 \mu \mathrm{m}$ and geared motor speed with PWM control were 40rpm, 81rpm, 126rpm, 172rpm, respectably.

Second, rectified voltage and filtered voltage with condenser were compared.

Third, electrical energy using Figure 3 was accumulated to the super capacitor for three days and accumulated energy was analyzed. Experiment in the range of motor
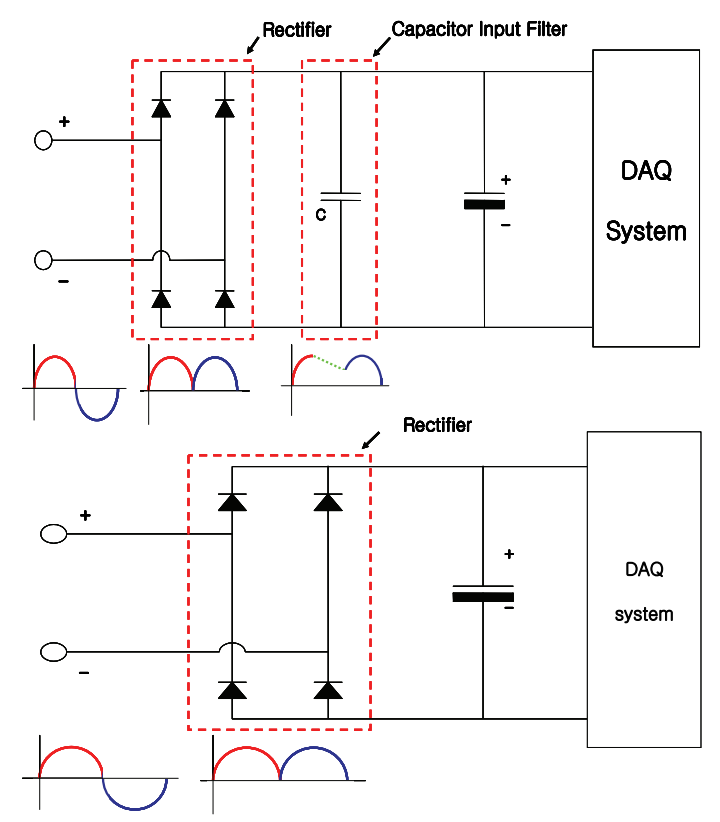

Figure 3. Schematic diagram of energy storage circuit.

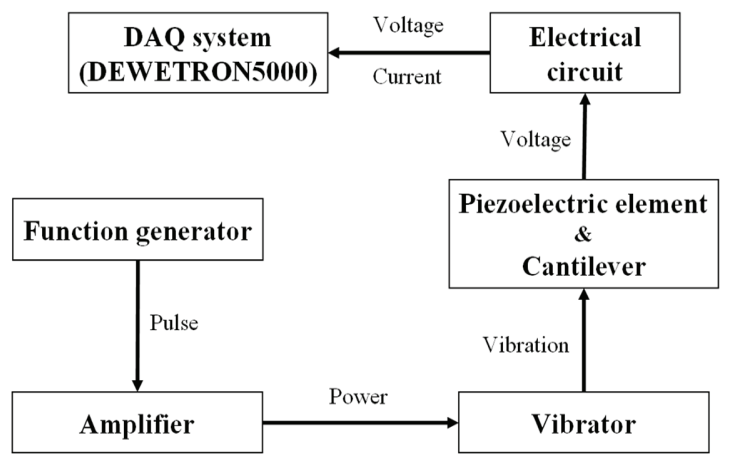

Figure 4. Block diagram of experimental setup. speed 126rpm with piezoelectric element displacement $500 \mu \mathrm{m}$ was operated.

\subsection{Type of Vibrator}

Figure 4 shows a block diagram of experimental setup and equipments. The experimental equipments which measure the generated electric energy, current and voltage from piezoelectric element which is operated by vibrator are a power analyzer (NORMA 4000) and a data acquisition system (DEWETRON-5000). A used vibrator is a magnetic type, and frequency and displacement gain can be adjusted by amplifier.

Figure 5 shows a schematic of cantilever with a piezoelectric element for experiment. The material of cantilever is an aluminum and four kinds of cantilever which sizes are $150 \mathrm{~mm} \times 13 \mathrm{~mm} \times 1.5 \mathrm{~mm}, 170 \mathrm{~mm} \times 13 \mathrm{~mm} \times 1.5 \mathrm{~mm}, 190$ $\mathrm{mm} \times 13 \mathrm{~mm} \times 1.5 \mathrm{~mm}, 210 \mathrm{~mm} \times 13 \mathrm{~mm} \times 1.5 \mathrm{~mm}$ were experimented, respectively. The used piezoelectric element is bimorph type ceramic (PI, PL140.10, piezoelectric constant $\mathrm{d}_{31}=-130 \times 10^{-12} \mathrm{C} / \mathrm{N}, \mathrm{kp}=55 \%$ ) with a size of $45 \mathrm{~mm} \times$ $11 \mathrm{~mm} \times 0.6 \mathrm{~mm}$.

Figure 6 shows a photo view of experimental setup which consists of an electromagnetic type vibrator with an energy harvesting equipment, a data acquisition system, a function generator and a camera.
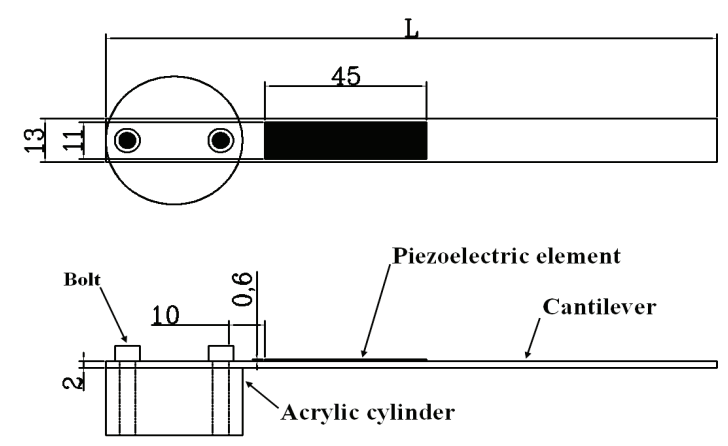

Figure 5. Schematic of cantilever with a piezoelectric element.

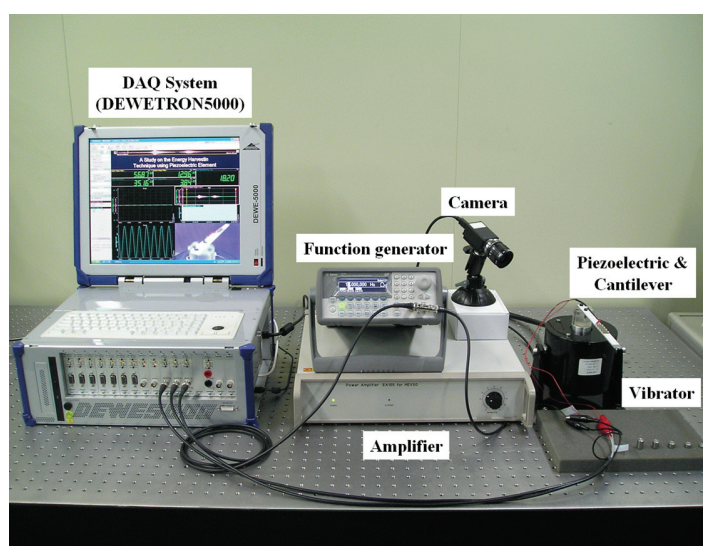

Figure 6. Photo view of experimental setup. 
Figure 7 shows the electric circuit used to measure the output of electric current and the electric power generated from the piezoelectric element.

In order to drive the vibrator, the output terminal of the amplifier for the vibrator was linked to the vibrator, and then the output terminal of the function generator was linked to the vibrator as well. The signal coming out of the function generator was set to $\pm 1 \mathrm{Vpp}$, and the output voltage of the amplifier was set to $\pm 12 \mathrm{~V}$ for the experiment. At this time, the frequency of the function generator ranged from $10 \sim 200 \mathrm{~Hz}$, which was within the frequency range of the vibrator. The natural frequency of the cantilever was changed to be $0.1 \mathrm{~Hz}$ unit of the

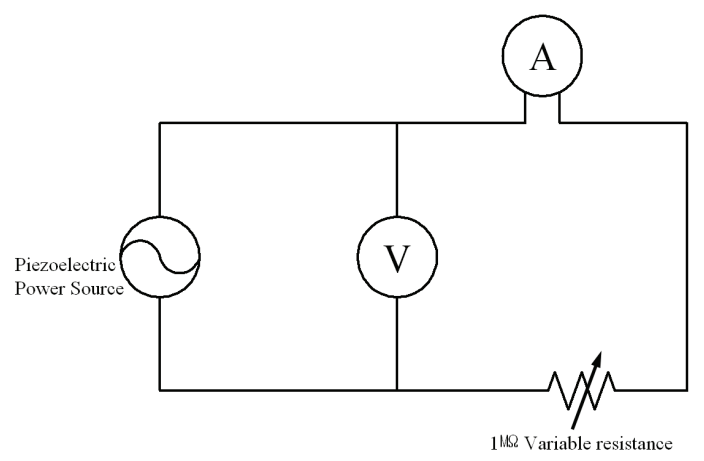

Figure 7. Electric circuit for power measurement.

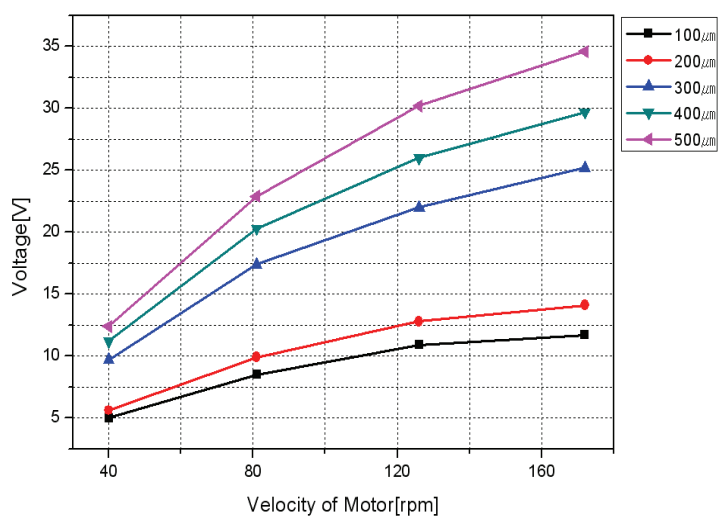

Figure 8. Output voltage by motor speed variation.

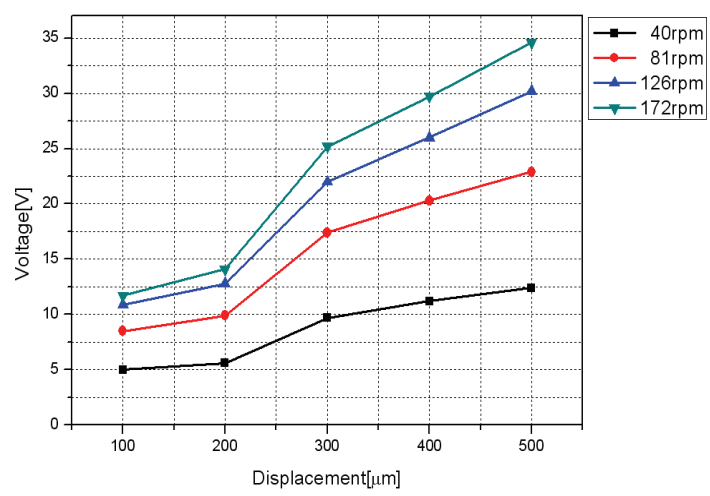

Figure 9. Output voltage by displacement variation. function generator. As the natural frequency, we selected the frequency of the function generator when the voltage generated from piezoelectric element was at a peak.

In order to verify the manner in which the characteristics of the voltage were affected by changes in length and weight at the end of the cantilever, we chose a length from among 150,170,190, and $210 \mathrm{~mm}$ in turn, and changed the weight from 0 , to $2.22,4.34,5.87,8.66$, and to $11.01 \mathrm{~g}$, in that order. The electric power generated from the piezoelectric cantilever was calculated by measuring electric current and voltage generated at each part when changing the resistance value.

\section{Results and Discussion}

\subsection{Type of Geared Motor}

Figure 8 and Figure 9 are the experimental results of the output voltage characteristics by variation of the piezoelectric element displacement and motor speed. From the Figure 8 and Figure 9, we can know that the output voltage of the piezoelectric element is proportional to the increment of the piezoelectric element displacement and the motor speed. In order to get a static characteristic, the analysis for improvement of the brittleness and the energy density must be researched.

Figure 10 shows the accumulated energy characteris-

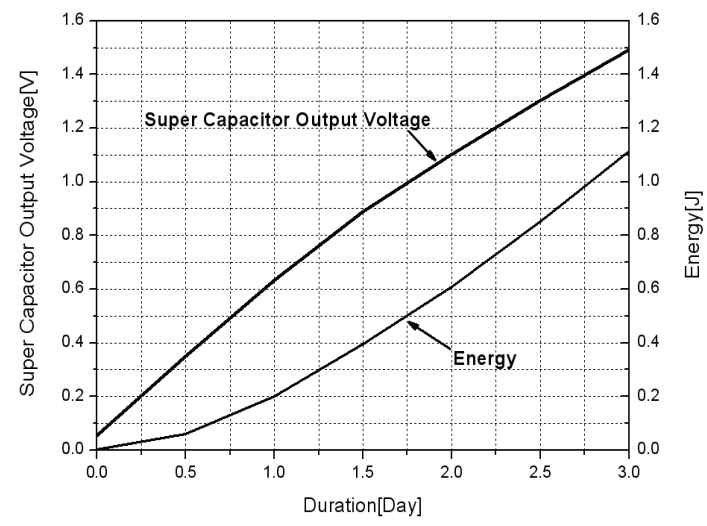

(a)

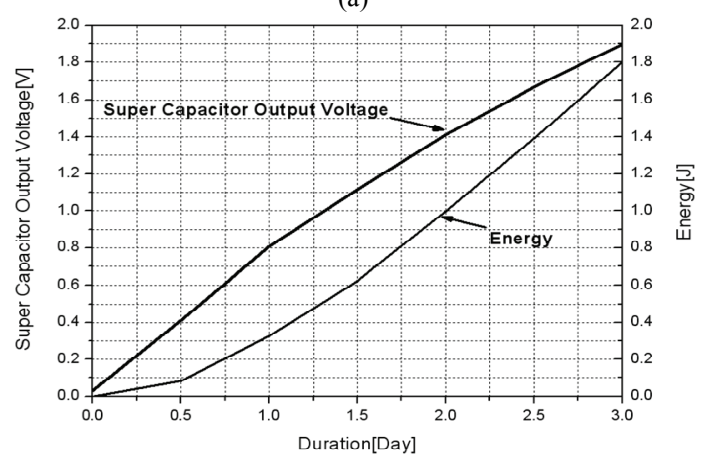

(b)

Figure 10. Energy harvesting characteristics. (a) With rectified \& filtered circuit; (b) With rectified circuit. 
tics. Experiment was accomplished under the condition of the fixed motor speed, 126rpm and piezoelectric element displacement, $500 \mu \mathrm{m}$. Electrical energy was accumulated for three days and the characteristics of rectified and filtered one were compared. Energy of the Figure 10 was calculated using Equation (1).

$$
E_{e}=\frac{1}{2} c_{r} V_{r}^{2}
$$

where, $E_{\mathrm{e}}$ : Charged energy in the super capacitor, $c_{r}$ : Capacitor capacity, $V_{\mathrm{r}}$ : Output voltage.

The thin line of Figure 10 shows the energy derived from the Equation (1). Charged energy using filtered circuit is $1,116 \mathrm{~mJ}$ and charged energy using rectified circuit is $1,801 \mathrm{~mJ}$. From the Figure 10, we can know that the capacitor is an important parameter and optimal circuit of energy conversion system using windmill is needed.

Figure 11 shows the full charge characteristics of the super capacitor and experiment was accomplished under the same condition of Figure 11. The maximum charge voltage of used capacitor is $5 \mathrm{~V}$. It was confirmed from the Figure 11 that charging time for $5 \mathrm{~V}$ is 16 days and charged energy is $12,720 \mathrm{~mJ}$. This means that charged energy per an hour is $33.125 \mathrm{~mJ}$.

Table 1 shows the wireless sensor system consists of microprocessor, temperature sensor and wireless transmission module. And this table shows operating voltage, consumption current and consumption power for one time transmission of the temperature data.

The minimum energy for one time transmission of the

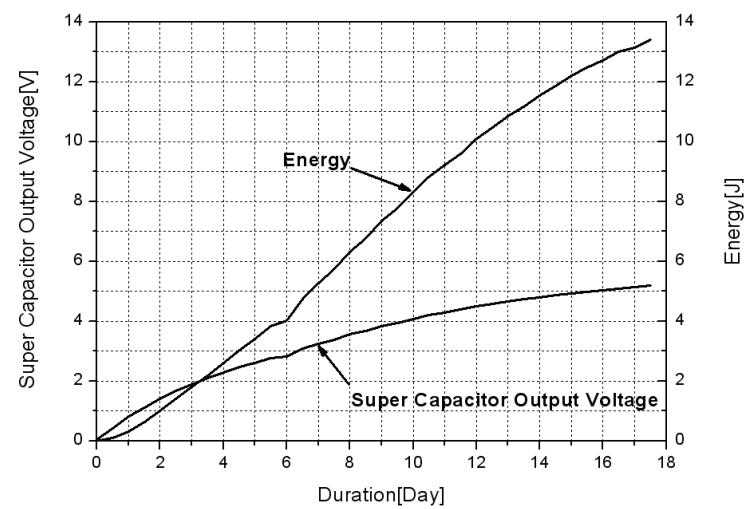

Figure 11. Energy harvesting characteristics of piezo-electric element.

Table 1. Consumption power of energy conversion system.

\begin{tabular}{|c|c|c|c|c|}
\hline \multirow{2}{*}{ Items } & $\begin{array}{c}\text { Operating } \\
\text { Voltage } \\
{[\mathrm{V}]}\end{array}$ & $\begin{array}{c}\text { Consumption current } \\
{[\mathrm{mA}]}\end{array}$ & $\begin{array}{c}\text { Consumption power } \\
{[\mathrm{mW}]}\end{array}$ & Remarks \\
\hline \hline MCU(PIC16F) & 5 & 7 & 35 & Operating \\
\cline { 3 - 5 } & 5 & 25 & $125(10 \mathrm{~ms})$ & Source/Sink \\
\hline Sensor & 5 & 3 & 5 & Temp. sensor \\
\hline \multirow{2}{*}{ Tx Module } & 5 & 4 & 15 & Supply \\
\cline { 3 - 5 } & \multirow{2}{*}{ Full load power consumption[mW] } & $20(10 \mathrm{~ms})$ & Transmission \\
\hline \multicolumn{5}{|r}{} \\
\hline
\end{tabular}

temperature data using a wireless system is calculated by Equation (2).

$$
\begin{aligned}
U_{\min }= & 55(\mathrm{~mW}) \cdot 600(\mathrm{~ms})+145(\mathrm{~mW}) \cdot 10(10 \mathrm{~ms}) \\
= & 34.45(\mathrm{~mJ})
\end{aligned}
$$

From the Equation (2), consumed energy for one time transmission of the temperature information is 34.45 $(m J)$.

Finally, we can know from this study results that there are many energy source such as vibration, wind power and wave power. Also, these can be used to the energy harvesting system using smart device like piezoelectric element.

\subsection{Type of Vibrator}

Figure 12 indicates the natural frequency measured by changing the length and weight at the end of the cantilever. When there was no mass applied, the natural frequency stood at $132.6,99.5,58.9$, and $50.0 \mathrm{~Hz}$ for weights of 0 , to $2.22,4.34,5.87,8.66$, and $11.01 \mathrm{~g}$, respectively, from which it can be observed that as the weight at the end increases, the natural frequency decreases.

The natural frequency of the cantilever(fn) is known to exist in $\mathrm{N}$ inverse proportion to the weight applied at the end. The experimental results are consistent with this theory. It is confirmed that as the weight applied at the end increased, the natural frequency was lessened. In addition, as the length of the cantilever was longer, the natural frequency became lower.

Figure 13 shows the results of measuring output voltage depending on the weight applied at the end of the cantilever. The weights applied were 0, 2.22, 4.34, 5.87, 8.66 , and $11.01 \mathrm{~g}$, respectively. The output voltage was written using RMS values. It is confirmed that as the weight applied at the end of the cantilever increased, the natural frequency became lower.

The experimental results from Figure 13 (a) to (d) con-

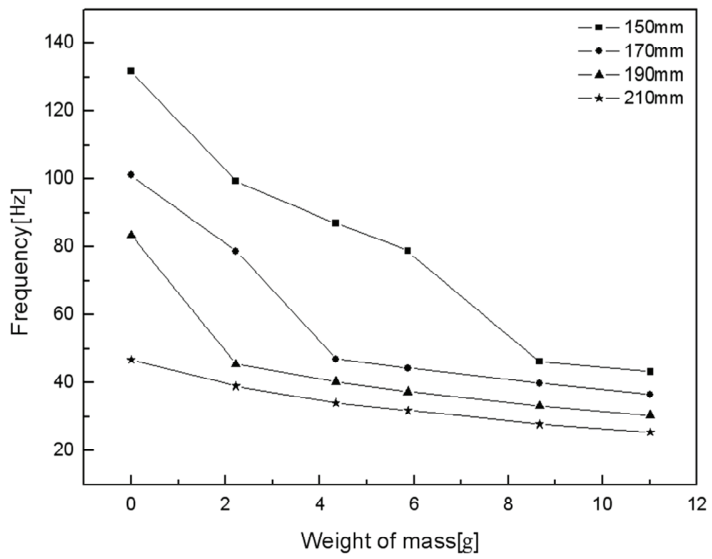

Figure 12. Resonance frequency characteristics by change of cantilever length and mass. 


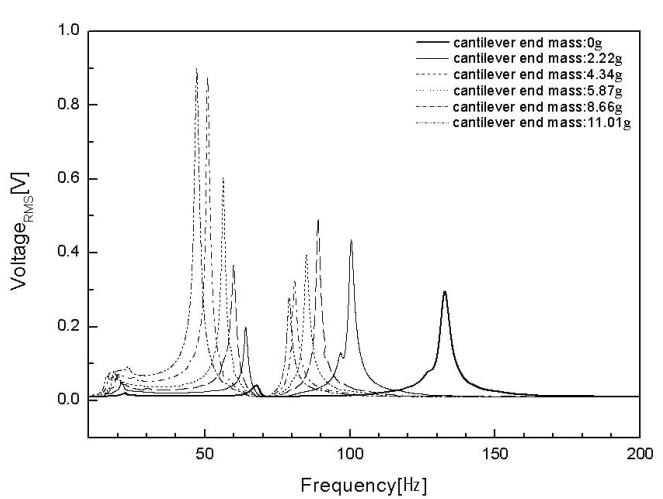

(a)

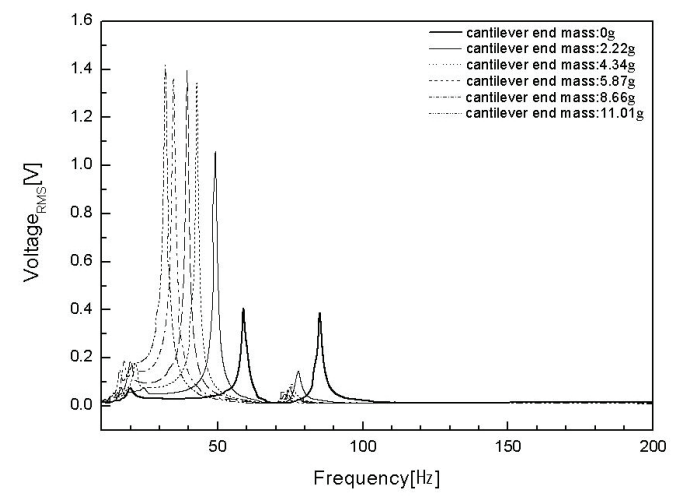

(c)

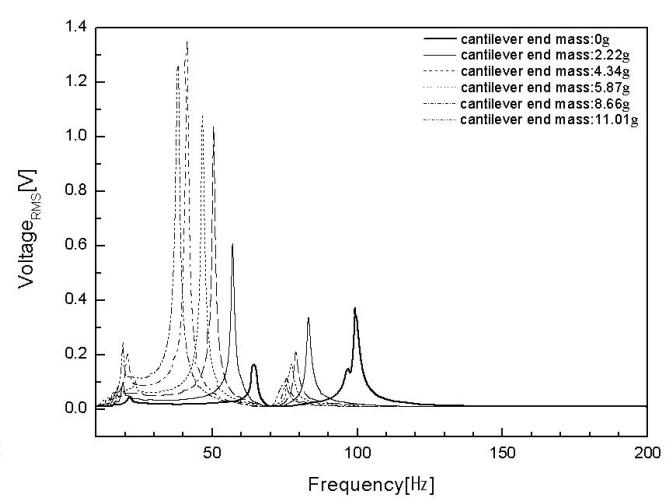

(b)

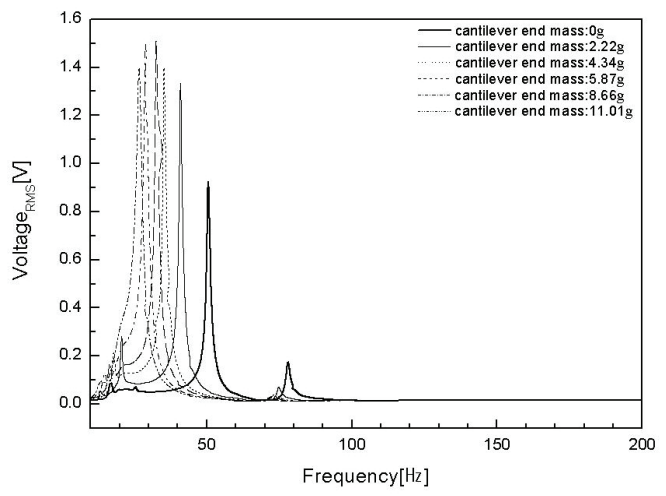

(d)

Figure 13. Output voltage characteristics by weight variation. (a) Cantilever length, 150mm; (b) Cantilever length, 170mm; (c) Cantilever length, 190mm; (d) Cantilever length, $210 \mathrm{~mm}$.

firm that as the weight applied at the end of the cantilever increased, the natural frequency became lower. The experiment also confirms that two distinct natural frequencies were shown, which was caused by the property of the aluminum. The output voltage was higher at the lower natural frequency than at the higher natural frequency. When the length of the cantilever was $150 \mathrm{~mm}$, a heavier weight applied at the end of the cantilever resulted in a higher output voltage. We assumed that when the length was 170,190 , or $210 \mathrm{~mm}$, the output voltage would be higher as the natural frequency became lower, but as the weight changed from 0 to $5.87 \mathrm{~g}$, the output voltage gradually became higher. On the other hand, when the weight was 8.66 or $11.01 \mathrm{~g}$, the output voltage became lower or constant. As shown in Figure 13, when the weight applied at the end of the cantilever was $11.01 \mathrm{~g}$, the natural frequency became lower, while the output voltage became higher at a length ranging from 150 to $190 \mathrm{~mm}$. On the other hand, when the length was $210 \mathrm{~mm}$, the output voltage was lower than that at $190 \mathrm{~mm}$. The experimental results tell us that if the length of the cantilever is too long, or if the weight at the end of the cantilever is too heavy, we may be able to lower the natural frequency, but we cannot efficiently generate energy.

Figure 14 and Figure 15 show the measured output voltage and electric power, and the natural frequency stood at 58.9 and $31.9 \mathrm{~Hz}$ when the weight applied at the end of the cantilever was $0 \mathrm{~g}$ and $11.01 \mathrm{~g}$, respectively.

As the value of the variable resistance increased, the output voltage became gradually higher and then constant. At each of resistance, $678 \Omega$ and $993 \Omega$, the maximum power was obtained. At this time, electric impedance seems to have occurred. When the output was at the peak, the impedance of the piezoelectric element can be calculated using the following Equation (3).

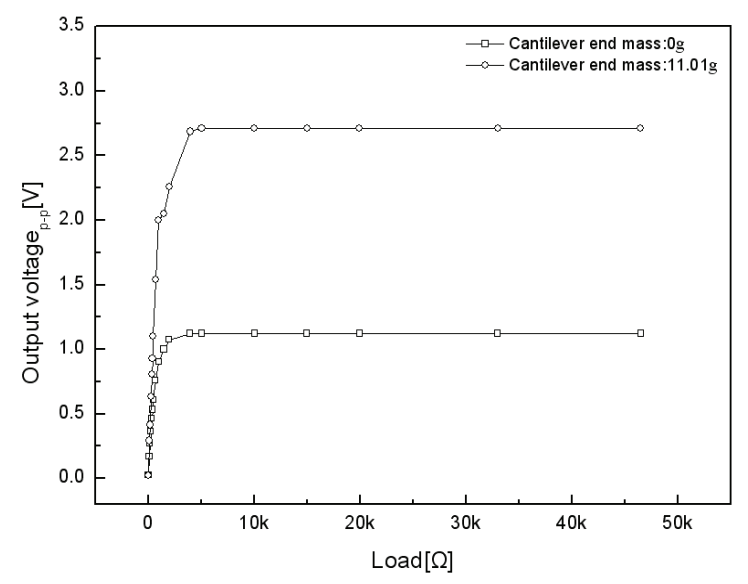

Figure 14. Variation of measured output voltage by electrical load. 


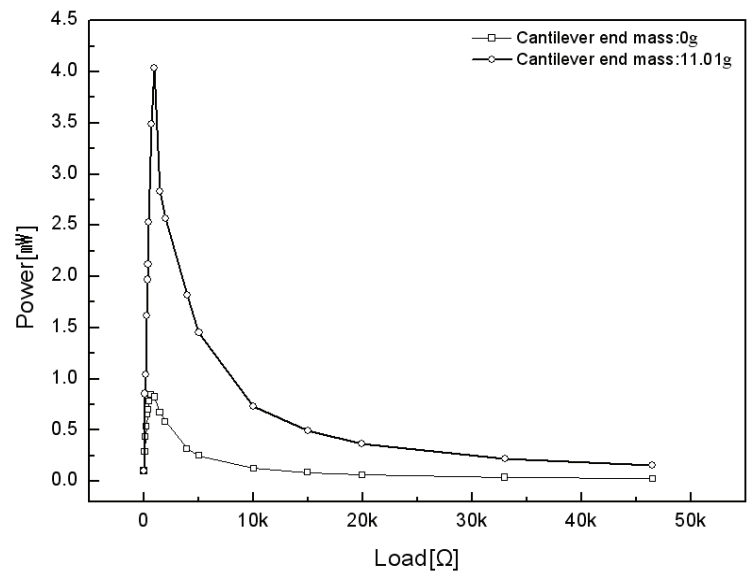

Figure 15. Variation of measured power by electrical load.

$$
Z=\frac{1}{2 \pi f C}
$$

$Z, f$, and $C$ represent the impedance of the cantilever, input frequency, and the electricity capacity of the ceramic, respectively. When calculated using the Equation 3 above, the impedance of the cantilever was calculated to be $675.5 \Omega$ and $1.247 \mathrm{k} \Omega$, respectively, which were shown to be almost identical to the experimental results. When $11.01 \mathrm{~g}$ was applied, the electricity capacity was identical to that when $0 \mathrm{~g}$ was applied, while the natural frequency became lower than that when no weight was applied, so that the level of impedance at which the electric power became the highest became higher. When the length of the cantilever was $190 \mathrm{~mm}$, and 0 and $11.01 \mathrm{~g}$ of weight were separately applied, the electric power stood at $0.845 \mathrm{~mW}$ and $4.036 \mathrm{~mW}$, respectively. This represents a 4.78 times difference in electric power between the application of $0 \mathrm{~g}$ and the application of $11.01 \mathrm{~g}$. This result demonstrates that when a heavier weight is applied at the end of the cantilever, the electric power generated becomes higher.

Figure 16 indicates the experimental results of the study, "Frequency Tuning of Unimorph Cantilever for Piezoelectric Energy Harvesting," which is provided for

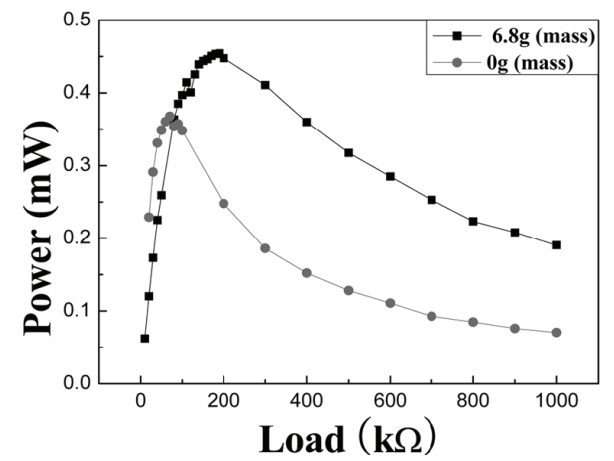

Figure 16. Result of "Frequency tuning of Unimorph cantilever for piezoelectric energy harvesting [9]". the sake of comparison with this experimental result. However, the size of the piezoelectric element, the piezoelectric constant, electromechanical coupling coefficient, material, size and the weight applied at the end of the cantilever used for this study were different from those used for the aforementioned study, and thus several variables should be taken into account in order to compare the two studies. Nevertheless, the natural frequency becomes lower when a heavier weight is applied than when a lighter weight is applied, an identical tendency shown in both studies. The piezoelectric element used for this study generated nine times more electricity than that of the piezoelectric element shown in Figure 16. It can be analyzed that the output of electricity was improved through such variables as the piezoelectric constant and permittivity, and the size of the cantilever.

\section{Conclusions}

The purpose of this study is to understand the characteristics of the energy harvesting devices using vibration or wind. The geared motor method depicts the windmill system and the vibrator is representive vibration source such as buildings, factories, vehicles and human body.

The geared motor method is to simulate the windmill system and consists of geared motor, cam, and energy harvesting equipment with controller. In this study, the equivalent speed of the geared motor by windmill speed was controlled by controller and the output energy from the piezoelectric element with a cantilever was measured by data acquisition system.

The vibrator method is representive the vehicle and consists of the vibrator and energy harvesting system with vibrator controller. In this case, the most important this is to reduce the vibration frequency of piezoelectric element because the environmental vibration source is very low about $300 \mathrm{~Hz}$.

In this study, the piezoelectric element with a cantilever and with a mass for reducing the natural frequency of the energy harvesting system was fabricated and experimented. The relation between the geared motor method and the vibrator is to get a green energy from the vibration source and to use waste energy application techniques. The proposed model can be used to predict performance and to provide insights for improving the designs of energy harvesting for the windmill and vibration systems. It will also be useful in the design and analysis of control systems that utilize this in high performance application of the windmill and vibration. Also, this study suggests that the stored energy to the capacitor or secondary battery can be used to the USN and WSN.

\section{References}

[1] A. Joseph, Paradiso, and T. Starner, "Energy scavenging for mobile and wireless electronics," IEEE Pervasive 
Computing, Vol. 4, Issue 1, pp.18-27, 2005.

[2] R. Stephen, Platt, S. Farritor, and H. Haider, "On lowfrequency electric power generation with PZT ceramics," IEEE/ASME Transactions on Mechatronics, Vol. 10, No. 2, pp. 240-252, 2005.

[3] T. Starner, "Thick clients for personal wireless devices," IEEE Computer, Vol. 35, No. 1, pp.133-135, 2002.

[4] S. R. Anton and H. A. Sodano, "A review of power harvesting using piezoelectric materials (2003-2006)," Smart material and Structures, Vol. 16, No. 3, pp. 1-21, 2007.

[5] J. Kymissis, C. Kendall, J. Paradiso, and N. Gershenfeld, "Parasitic power harvesting in shoes," Proceeding of the Second IEEE International Conference on Wearable Computing (ISWC), pp. 132-139, 1998.

[6] R. P. Stephen, S. Farritor, K. Garvin, and H. Haider, "The use of piezoelectric ceramics for electric power generation within orthopedic implants," IEEE/ASME Transactions on Mechatronics, Vol. 10, No. 4, pp. 455-461, 2005 .

[7] S. Priya, "Modeling of electric energy harvesting using piezoelectric windmill," Applied Physics Letters, Vol. 87, No. 18, 184101-1-3, 2005.

[8] H. A. Sodano, G, Park and D. J. Inman, "Estimation of electric charge output for piezoelectric energy harvesting," Blackwell Publishing Ltd, Vol. 40, No. 2, pp. 49-58, 2004.

[9] H. C. Kim, H. C. Song, D.-Y. Jeong, H.-J. Kim, S.-J. Yoon, and B. K. Ju, "Frequency tuning of unimorph cantilever for piezoelectric energy harvesting," Korean Journal of Materials Research, Vol. 17, No. 12, 660-663, 2007. 